\title{
Logistics model for selecting road sections of a mining enterprise for equipping them with automated traffic control tools
}

\author{
Aleksandr Afanasyev ${ }^{1 *}$, Aleksey Egoshin ${ }^{2}$, Sergey Alekseev ${ }^{3}$ \\ 1Saint Petersburg mining University,21 Line, 199106, St. Petersburg, Russia, \\ ${ }^{2}$ General A. V. Khrulev Military Logistics Academy, 8, Admiral Makarov embankment, 199034, St. Petersburg, Russia, \\ ${ }^{3}$ Peter the Great Saint Petersburg Polytechnic University, 29, Politechnicheskaya st., 195251, St. \\ Petersburg, Russia,
}

\begin{abstract}
The proposed model allows us to determine the sections and objects on the roads of mining enterprises that operate in the most intensive mode, in order to equip them with automated traffic control tools. The model is based on the logistic method of $\mathrm{ABC}$ and $\mathrm{XYZ}$ analysis, which allows determining such objects and areas with sufficient accuracy. In addition, the scientific novelty of this model is the choice of technical means not by two parameters, as in the classical logistics model, but by three. In addition, this model offers to determine the optimal number of technical means of traffic control, taking into account their cost and the required reliability. When optimizing the number of technical means of traffic control on the roads of mining enterprises, a linear programming model was used that minimizes the target function of total costs, taking into account the required reliability of technical means, while limiting their number used in performing traffic control tasks. The original distribution of technical means for the tasks of traffic control on the roads of mining enterprises is proposed.
\end{abstract}

\section{INTRODUCTION}

The territory of contemporary mining complexes can occupy considerable areas. Their area is possible to take up thousands of square kilometers. The road network is created for the vehicles movement within large areas, entry and exit to them. Intensive road traffic associated with the transportation of mined minerals, as well as the provision of processes associated with the operation of a mining enterprise, must be clearly and timely regulated to prevent road accidents and congestion $[1,2]$.

The desire of mining enterprises managers to fully control the road situation can lead to high costs of funds allocated to eliminate or minimize factors that affect the road traffic situation in the region. The ability to timely identify those road sections that require the organization of automated (or automatic) traffic control determines the potential effectiveness of the road traffic organization and safety management system on the road network of large mining enterprises $[3,4,5]$.

The need to equip the largest possible number of road sections with automated traffic control means will entail unnecessary expenditures of funds. When determining road sections on which it is necessary to install traffic lights, electronic road signs and indicators, as well as modern traffic control tools (traffic sensors, video recorders, etc.), the management of enterprises should proceed from the assumption that such traffic controls are not installed on every site, and on the most essential
[6].

Correct designation of road sections enables traffic control exactly in those places where it is required. Moreover, it can significantly save corporate funds.

$\mathrm{ABC}$-analysis of goods assortment is used in logistics to determine their importance in the total profit of a company. XYZ analysis is applied to compute the demand stability for a particular product. The conclusion about enhanced control over the supply and sale of a specific assortment group of goods is made on the basis of the outcomes of constructing an ABC-XYZ-analysis matrix $[7,8]$.

\section{MATERIALS AND METHODS}

A similar logistic model for selecting road sections for equipping them with automated traffic control tools based on the Pareto rule is proposed to define the significance of certain sections on the roads of mining enterprises and organizations. This model refers to statistical one and can be applied to the stratification of objects on the roads after collecting specific statistical information on the traffic intensity of vehicles and their throughput. Besides, it is possible to simulate the movement for the intensity parameters calculation in the absence of statistical information.

According to the model, the selection of sections consists in dividing all roads into groups due to traffic

*Corresponding author: a.s.afanasev@mail.ru 
intensity indicators by day time and days of the week, as well as the traffic load factor [9].

\section{RESULTS AND DISCUSION}

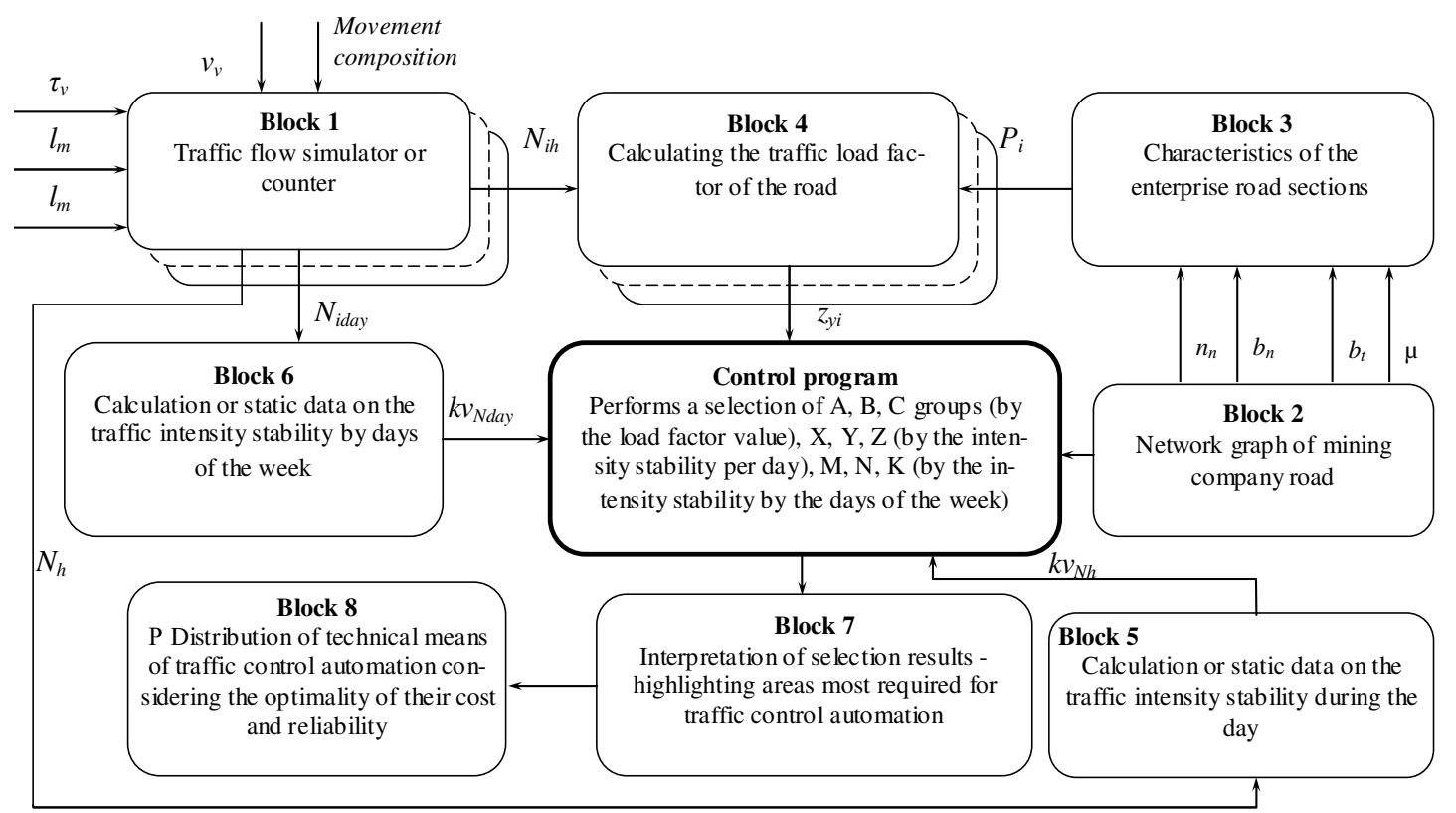

Figure 1.Logistic model structure for the selection of road sections for equipping them with automated traffic control tools

Block $l$ is intended for simulating traffic flow on roads.It is possible to obtain the traffic intensity on each characteristic road section by hours during the day and by days of the week, setting the time of vehicle arrivals to objects on the road, their length, speed, length of trailers, traffic composition, interval and dynamic dimensions, change of movement direction, etc. The collection of statistical information on the intensity for a day and a week with field observation of the road networks of a mining enterprise within particular time gives more accurate results[10].

Block 2simulates the road network of a mining enterprise. The road characteristics (number and width of lanes, presence and width of shoulders, coefficient of the wheel adhesion to the coating (depending on the coating material), visibility conditions, etc.) are taken into account when determining the road network and ultimately affect the throughput of the section or an object on the road.

Block 3is designed to identify and structure all sections and objects on the roads of a given mining enterprise. Besides, the road network of the mining enterprise is divided into peculiar sections where the characteristics of the road or traffic flow change take place.

Block 4provides processing of statistics on traffic intensity and throughput of each characteristic section or road object of a mining enterprise. The traffic load factor $z_{y i}$ is computed for each characteristic section.

$$
z_{y i}=\frac{N_{i, h}}{P_{i, h}},
$$

where $z_{y i}$ - traffic load factor oni-th section;
The model consists of eight interconnected blocks. The logistic model structure for the selection of road sections for equipping them with automated traffic control tools is shown in Figure 1. 
section, vehicle/hour;

$\bar{N}_{i, \text { week }}$ - average weekly traffic intensity on $i-t h$ section, vehicle/hour;

$n$ - day of the week.

Control program performs division of all characteristic sections of the road network of a mining company into groups.

The division into groups of $A, B$ and $C$ is made according to the value of the traffic load factor of road sections. The assignment to these groups is as follows. The absolute values of the road load factors are summed up with the traffic on all sections. Then, the load factor of each section is divided by the resulting sum of the coefficients, showing the share of the load factor of each section in the total amount.

$$
q_{i}=\frac{z_{y i}}{\sum_{i=1}^{m} z_{y i}} 100 \%,
$$

where $q_{i}$ - share of the load factor of each $i-$ thsection, $\%$.

$m$-total number of the road networksections, pcs.

The selected objects are arranged in descending order of the share of the road load factor starting from the maximum value. The Pareto curve is constructed on the results of the collected statistics [7]. It is shown in Figure 2 in the following coordinates: abscissa axis - sections of the road network; ordinate axis - the share of the load factor of each section with an accrued method in percent.

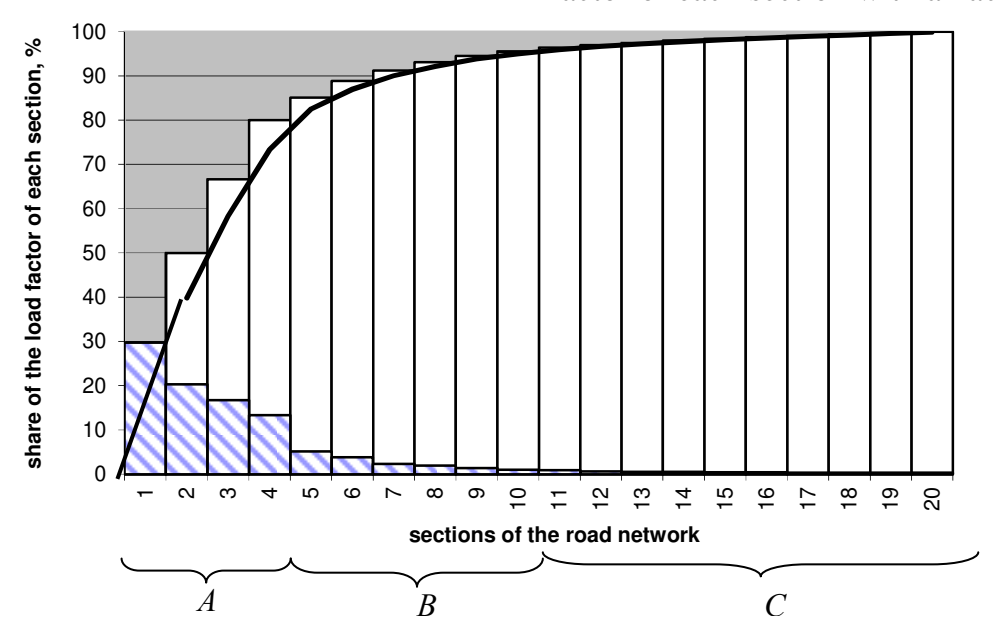

Figure2.Elicitation of groups of $A, B$ and $C$ road sections

Further, the groups of $A, B$ and $C$ factors are distinguished $[8,11,12]$. The first $20 \%$ of objects with the highest value of the road load factor belong to group $A$. The next $30 \%$ of objects with a lower value of the road load factor refer to group $B$. All the remaining 50\% of objects with an even lower value of the road load factor apply to group $C$.

Then the dynamics analysis of changes in the hourlong intensity is carried out according to the time of day $(X, Y, Z)$ and daily intensity according to the days of the week $(M, N, K)$. The low amplitude of fluctuations in the hour-long and daily intensity with all other things being equal, indicates the traffic intensity stability on this road section. In this regard, we construct the XYZ curve (and similarly to $\mathrm{M}, \mathrm{N}, \mathrm{K}$ ), which is the graph shown in Figure 3, differentiating the total number of sections into groups $X, Y, Z$ and $M, N, K$ based on the occurrence stability.

Further, the groups of $X, Y$ and $Z$ factors are distinguished $[10,13,14]$ :

group $X(M)$ includes road sections with an intensity variation coefficient within $0 \leq v \leq 10 \%$;

group $Y(N)$ - road sections with an intensity variation coefficient within $10 \% \leq v \leq 25 \%$;

group $Z(K)$-road sections with an intensity variation coefficient within $25 \% \leq v \leq \infty$.

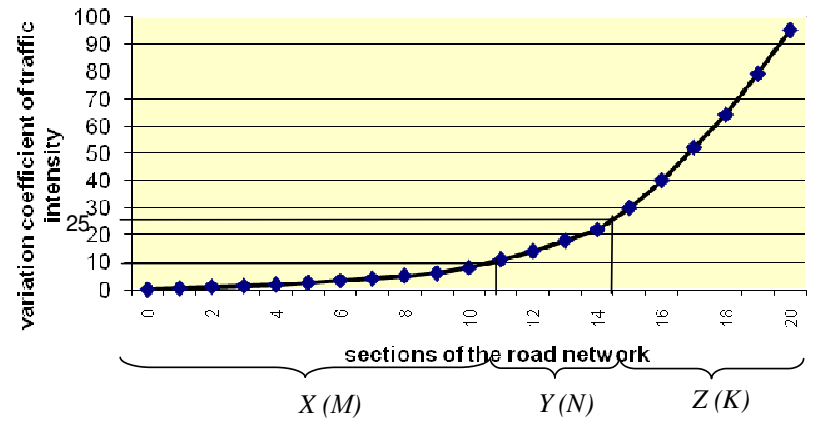

Figure 3.Elicitation of groups of $X, Y$ and $Z$ hazardous factors

If the traffic intensity indicator is stable, then the forecasting errors are less and the installation of automated traffic control tools has more priority in a particular section or object.

Block 7interprets the results of the section selection. The outcomes of the ABC, XYZ and MNK analysis, enclosed in a three-dimensional matrix, shown in Figure 4 , allow identifying groups of sections, the equipment of which requires the installation of automated traffic control tools. 


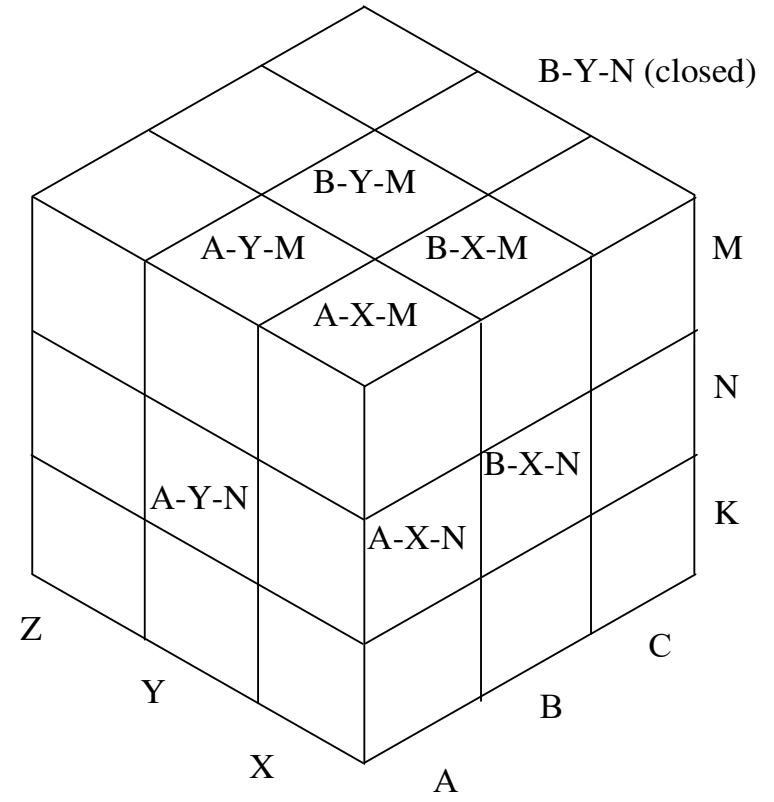

Figure 4.Three-dimensional matrix of hazardous groups

Having grouped the road sections, we select the following groups:

$A-X-M$ - a group of road sections of a mining enterprise with the highest load factor and the most stable traffic intensity by time of day and days of the week, requiring priority equipping with automated (automatic) traffic control tools.

$A-X-N, A-Y-M, A-Y-N, B-X-N, B-X-M, B-Y-M, B-Y-$ $N$ - groups of road sections requiring attention to be equipped with traffic control tools.

The section and object groups of the road network of the mining enterprise (especially the A-X-M group), allocated according to given characteristics, require the main attention of the enterprises' managers for the placement of automated traffic control tools on these sections.

Block 7distributes technical means according to traffic control tasks in technical solutions.

The distribution is performed to form the structure and composition of technical solutions depending on the required tasks of technical means involved in the motion control process. Table 1 is applied in this case.

The distributional integer task of linear programming can be applied as a mathematical formulation of the hardware distribution. The problem statement is as follows.

Let there be $m$ tasks $A_{i}(i=1, \ldots, m)$ of controlling the flow of enterprise vehicles, performed by an automated traffic control system; ntypes of technical means $B_{j}(j=1 . . n)$ can be used to complete each of the tasks. The cost $c_{i j}$ of each technical means is known asjthtypeperforming the $i$-thtask of traffic control and ensuring its safety. Besides, the stability $p_{i j}$ of each technical means of $j$-thtype is known or can be calculated on the basis of past experienceto perform the $i$-thtask. It is required to draw up a plan for the distribution of technical means that allows fulfilling the tasks of traffic control and ensuring its safety with minimum cost and maximum stability of the technical means operation.

Table 1.Distribution of technical means by traffic control tasks in technical solutions [3].

\begin{tabular}{|c|c|}
\hline $\begin{array}{c}\text { Traffic control } \\
\text { tasks }\end{array}$ & Technical means \\
\hline Decision-making & $\begin{array}{l}\text { computers; } \\
\text { servers; } \\
\text { system blocks; } \\
\text { mini and microcomputers; } \\
\text { controllers. }\end{array}$ \\
\hline $\begin{array}{l}\text { Communication } \\
\text { and information } \\
\text { security }\end{array}$ & $\begin{array}{l}\text { data cables; } \\
\text { receiving and transmitting } \\
\text { antennas; } \\
\text { data receiving and transmitting } \\
\text { units; } \\
\text { radio stations; } \\
\text { data converting units; } \\
\text { commutators; } \\
\text { modems; } \\
\text { routers; } \\
\text { data encryption and decryption } \\
\text { units; } \\
\text { authentication blocks. }\end{array}$ \\
\hline Management & $\begin{array}{l}\text { traffic lights; } \\
\text { electronic pointers; } \\
\text { electronic multi-position road } \\
\text { signs; } \\
\text { electronic information boards; } \\
\text { driven milestones; } \\
\text { LED cords; } \\
\text { voice and telephony devices; } \\
\text { loudspeaker devices; } \\
\text { barriers; } \\
\text { access control devices. }\end{array}$ \\
\hline Control & $\begin{array}{l}\text { sensors: motion, capacity, } \\
\text { magnetic, infrared, laser; } \\
\text { camcorders; } \\
\text { number scanners; } \\
\text { radio frequency tags; } \\
\text { car recorders or trackers (GPRS } \\
\text { or satellite). }\end{array}$ \\
\hline $\begin{array}{l}\text { Informing, } \\
\text { positioning, } \\
\text { navigation }\end{array}$ & $\begin{array}{l}\text { electronic information boards; } \\
\text { electronic movement circuits; } \\
\text { mnemonic diagrams; } \\
\text { outdoor and indoor monitors; } \\
\text { information desks for medical } \\
\text { or technical services; } \\
\text { navigators. }\end{array}$ \\
\hline Auxiliary & $\begin{array}{l}\text { accumulators; } \\
\text { power supplies; } \\
\text { current generators; } \\
\text { sets of power cables and wires. }\end{array}$ \\
\hline
\end{tabular}

An optimization linear model for the distribution of technical means for traffic control tasks can be represented in the following form:

goal function 


$$
z=\sum_{i=1}^{m} \sum_{j=1}^{n} k_{i j} c_{i j} x_{i j} \rightarrow \min ,
$$

under the following restrictions

$$
\begin{gathered}
x_{i j}=1,2, \ldots, k, \\
\sum_{j=1}^{n} x_{i j} \leq a_{i}, i=1,2, \ldots, m ; \\
\sum_{i=1}^{m} x_{i j}=b_{j}, j=1,2, \ldots, n ;
\end{gathered}
$$

Where $x_{i j}$ - number of technical means of the $j$-th type, designed to perform the $i$ - $t$ th task of traffic control;

$c_{i j}$ - cost of a technical means of the $j$-th type, performing the $i$-th task of traffic control;

$a_{i}$ - amount of technical means that can be allocated to complete the $i$-th task;

$b_{j}$-need for technical means of the $j$-th type to perform traffic control tasks;

$k_{i j}$ - coefficient considering the reliability of the $j$ - $t h$ technical means when performing the $i$-th task.

$$
k_{i j}=\frac{1}{p_{i j}}, 0<p_{i j}<1
$$

where $p_{i j}$ - reliability of operation of the $j$-th type technical means when performing the $i$-th task.

Restrictions (5)-(8) in this model have the same physical meaning as in the classical distribution task [15].

The solution to this problem of substantiating the optimal distribution of technical means, taking into account the reliability of their work, is as follows. The formation of coefficients matrix $K=\left\|k_{i j}\right\|$, considering the operation reliability of the $j$-th type technical means when performing $i$-th task is provided at the solution first step. Reliability indicators are taken from the technical characteristics of the device.

Further, the coefficients matrix of $C=\left\|c_{i j}\right\|$ functional and restrictions is formed.

Finding a feasible solution and its subsequent optimization is carried out by known methods for solving the distribution task of linear programming [15].

\section{Conclusion}

The logistic model for the selection of road sections for equipping them with automated traffic control tools will ensure the organization and safety of road traffic on the most complicated sections with limited traffic capacity. However, the application of the proposed model in practice requires a comprehensive study of the joint work of technical means of traffic control automation both at a local object and a section of the road and the road network of the mining enterprise as a whole.

The scientific novelty of the model lies in the fact that it offers a new approach to data analysis using logistic methods.Moreover, a new coefficient has been introduced into the optimization model of linear programming, which makes it possible to select those road sections that need to be equipped with automated technical means of traffic control and to calculate their required number for traffic control on road sections of mining enterprises considering the unhindered passage of the required volumes of movement and its safety maintenance.

The theoretical significance of the model is a theory further development of automated control of traffic flows in terms of creating systems and automated complexes for traffic control in transport communications.

Thus, the use of a logistic model for the selection of road sections to equip them with automated traffic control tools will enable the managers of large mining enterprises to organize uninterrupted and safe traffic on the roads to organizations with respect to the costs optimization of their acquisition and reliability.

\section{References}

1. S.V.Alekseev, D.L.Simonov, A.N.Tolstikov Materials of the Anniversary International Scientific and Practical Conference. "Transport of Russia: Problems and Prospects - 2020.»PP. 191-194.(2020).

2. A.S.Afanasev, N.A.Ermoshin, A.T. Zmeev International Scientific and Practical Conference "Innovations and Prospects for the Development of Racing Engineering and Electromechanics: IPDME-2018.» (St. Petersburg,2018).

3. Organization and road safety in large cities. Collection of reports of the ninth international scientific and practical conference.(St. Petersburg: SPbSUACE, 2010).

4. A.S. Afanasyev, A.M. Egoshin, S.V. Alekseev Journal of Physics: Conference Series Krasnoyarsk Science and Technology City Hall of the Russian Union of Scientific and Engineering Associations,33021.(2019).

5. S.N. Korkin. Method for assessing the design of off-road vehicles by the magnitude of the destructive effect on the soil, $\mathrm{PhD}$ dissertation,MSTU (MSMBU).(2009)

6. N.A.Ermoshin, Iu.G.Lazarev Defense technology issues. Series 16: Technical means of countering terrorism. Scientific and Production Association of Special Materials, St. Petersburg).

7. A.M. Gadzhinskii Logistics. (Moscow: Publishing and Trade Corporation «Dashkov and $\mathrm{K} »$, 2005).

8. A.M. Gadzhinskii Workshop on logistics. (Moscow: Publishing and Trade Corporation «Dashkov and K», 2005).

9. N.I.Bolgarov, N.A.Ermoshin, R.G.Ismiatulin, S.L. Rudnitskii Adaptation of transport construction organizations to changing conditions. Modern problems of improving the work of railway transport, (Publishing house: Moscow State University of Railways of Emperor Nicholas II, 2019). 
10. D.S. Bukatov Bulletin of the Volsk Military Institute of Material Support: military scientific journal.3(51), (2019).

11. Iu.D. Kravets Regional aspects of management, economics and law of the Northwestern Federal District of Russia.4 (51), (2020).

12. Iu.G.Lazarev, D.L.Simonov, A.N. Novik Technical and technological problems of service.1(35), (2016).

13. T.Kh.Kurbanov, M.V.Martynov, V.A. Tokarev Economics and Entrepreneurship.11(88), (2017).

14. A.V.Babenkov, P.M. SobolevBulletin of the Military Academy of Material and Technical Support named after the General of the Army A.V. Khrulev.2(18), (2019).

15. Dzh.Dantsig Linear programming, its applications and generalizations. (Moscow: Publishing house «Progress», 1966). 